\title{
Estimation of water vole abundance by using surface indices
}

\author{
Patrick GIRAUDOUX, Bernard PRADIER, Pierre DELATTRE, \\ Sylvie DEBLAY, Dominique SALVI and Régis DEFAUT
}

Giraudoux P., Pradier B., Delattre P., Deblay S., Salvi D. and Defaut R. 1995. Estimation of water vole abundance by using surface indices. Acta Theriologica 40 : $77-96$.

A method to estimate the abundance of the fossorial form of the water vole Arvicola terrestris scherman (Shaw, 1801) has been developed, by using surface indices. Results are compared to the standard method of estimation using trap lines. These results show quantitatively that it is possible to differentiate reliably mole indices from water vole indices. Moreover, the two species are inclined to exclude each other. Even though water voles share the same galleries as moles, specific surface indices of the water vole occur for any density exceeding 2 ind/trap line (over 20 ind/ha). Several models of abundance estimation are put forward, all of them using linear multiple regressions. Correlations between the estimations from indices and the estimations from trap lines exceed 0.8 and the limits of using abundance classes are tested. Other limits are developed in the discussion. One of them is that the sampling intervals are saturated for densities exceeding $400 \mathrm{ind} / \mathrm{ha}$. The index method, which is easy to carry out, offers the definite advantage of being suitable to space and time scales otherwise incompatible with estimations from trap lines. For instance, it allows distribution maps from wide transects about areas of more than $25 \mathrm{~km}^{2}$ to be drawn, in less than two days.

Laboratoire d'écologie, Université de Bourgogne, BP 13821004 Dijon Cedex, France (PG, SD, DS); Laboratoire d'écoéthologie, Université de Montpellier II, CC64, 34095 Montpellier Cedex 05, France (PD); Service régional de protection des végétaux d'Auvergne, BP 45 Marmilhat 63370 Lempdes, France (BP); Service régional de protection des végétaux, et Fédération de défense contre les ennemis des cultures de Franche-Comté, BP 98925022 Besançon Cedex, France (RD)

Key words: Arvicola terrestris scherman, abundance index, estimation of abundance, Talpa europaea

\section{Introduction}

The estimation of animal abundance is one of the main difficulties of research in functional ecology. Methods based on capture-mark-recapture (CMR) or on catch effort have led, and still lead, to the development of numerous statistically unbiased models (e.g. Seber 1982). Providing the possibility to test the biological hypotheses underlying these models and therefore to check them carefully, these 
kinds of estimates are usually precise. However, carrying out these methods is technically difficult, and limits ecological investigations to only restricted space scales. As far as rodents are concerned, it is the scale of parcel or of station (Blondel's 1979 definition: $n \times 10 \mathrm{~m}$ ). Moreover to catch animals on this scale disturbs either individuals or populations, depending on whether CMR or catch effort methods is used (Wang 1993).

Perception levels where dynamic processes can be witnessed in rodent populations correspond to much wider scales, usually a regional scale $(n \times 10 \mathrm{~km})$ (Hansson and Hentonnen 1985, Delattre et al. 1988, Hanski and Tiainen 1988). The inadequacy between accurate but space limited estimation methods, and the range of phenomena under study is clear. Some authors have got round the problem - they evaluate species abundance by using activity indices. These kinds of estimations are easier to carry out so that working at wider scales is made possible. Anyway, the accuracy of measurements must always be considered in relation to the amplitude of the variations of the phenomenon: "sampling theory attempts to develop methods of estimation that provide, at the lowest possible cost, estimates that are precise enough for the purpose" (Cochran in Frontier 1983). Good results have been obtained for the common vole Microtus arvalis (Liro 1974, Mackin-Rogalska et al. 1986, Delattre et al. 1990), the bank vole Clethrionomys glareolus (Teivanen 1979), the Mediterranean pine vole Pitymys duodecimcostatus (Wang 1993), the Californian vole Microtus californicus (Lidicker and Anderson 1962), and the mole Talpa europaea (Mead-Briggs and Woods 1973). All of the chosen indices share the advantage of being characteristic of only one species, in the environment where they were studied.

The fossorial form of the water vole Arvicola terrestris scherman (Shaw, 1801), is a species which can reach very high densities in permanent grasslands of medium height mountains, and therefore causes serious damage to agriculture. The spreading of the population ${ }^{1}$ is only perceptible at the regional level (Pascal et al. 1985, Delattre et al. 1988, Giraudoux et al. 1990).

Four sampling methods for the water vole are now available (Pascal and Meylan 1986). Three are based on catch effort and one is based on CMR. Actually, the standard method - the most commonly used - is one of the first category (Pascal 1984, Rodolphe and Pascal 1985). It consists in setting two traps, if possible, in each of 20 successive squares arranged in a row, each square being $5 \times 5 \mathrm{~m}$. Afterwards, eight controls must be carried out, separated by 2 hours at least, and within $48 \mathrm{~h}$. Traps are set inside vole galeries previously detected by drilling. Prospecting galeries, trap setting and controls are time-consuming and it is impossible for two persons to set and control more than two trap lines in a day, each trap line being representative of 1 ha. To get an estimation of the number of rodents per $1 \mathrm{ha}$, the number of captures is multiplied by a correction coefficient

${ }^{1}$ Density of $A$. terrestris which exceeds two hundred ind/ha in grasslands and which widely and quickly spreads to all habitats around, including those which are not very favourable to the species. It also determines damage to grasslands that are considered economically unbearable by farmers. 
$k$, which roughly depends on the average size of the home range. We have little information on the variations of home range size according to density, which is, in fact, the parameter that is to be estimated. The coefficient $k$ also varies according to weather conditions and certainly according to seasons. Furthermore, within the estimation model, the probability of capture of each animal must be the same. This is far from being biologically confirmed. In fact those biological considerations are not taken into account in the practical use of statistical models and we have no idea of their consequences upon the estimation variability, which is supposed to be weak enough in comparison with the density variations to be measured. The statistical accuracy usually attributed to this kind of estimation is thus lessened to a certain extent. The coefficient $k$ is supposed to be equal to 8 to 10 when densities are close to 200 animals/ha (Pascal and Meylan 1986). In the end and despite the biological bias, this enables us to get a rough estimate of density. Actually, the best way to use this method is to compare all the numbers of captures obtained in similar ecological conditions when using a set of trap lines. Since biological bias are supposed to be equal estimations are comparable.

The main indices of the water vole activity are earth tumulus. However, their disadvantage is that they are often mistaken for molehills of Talpa europaea by inexperienced observers. Moreover, the two species can make use of the same galleries (Fritschy and Meylan 1980). Several scientific studies deal with the burrowing behaviour of the water vole (Airoldi 1976, 1981, 1992, Airoldi et al. 1976, Saucy and Meylan 1987, Saucy 1988, Airoldi and de Verra 1993) and of the mole (cited in Gorman and Stone 1990). Agricultural revues and crop protection services have published numerous technical notes and leaflets on the differences between the indices of the two species (Meylan 1965, 1977, SRPV et al. 1990, Meylan and Höhn 1991, inter alia). They are grounded mainly on empirical observations of agriculture experts, and, to some extent, on scientific studies on burrowing behaviours. Their goal is only to assess the presence or the absence of one species, by using activity indices such as tumulus features, the shape of gallery network, crop damage, etc. None of them provides statistical information on the reliability of assessments, none of them aims to estimate quantitatively water voles density, and none of them takes into account the possible coexistence of the two species when density is to be estimated (e.g. Mead-Briggs and Woods 1973). Therefore, it was impossible to know the reliability of indices in density estimation, e.g. when used by crop protection services in the water vole population monitoring programmes (Habert 1988). Moreover scientific studies on the water vole population distribution on a regional scale was jeopardized, as a reliable index method was not developed.

The present study aims to answer the four following questions: (1) statistically, what are the best criteria which differentiate the surface indices of the water vole from those of the mole, when the two species are coexisting? (2) what are the population conditions which allow the coexistence of the two species in the same gallery network? (3) which is the best linear combination of index variables to be 
correlated to the number of water voles captured by using the standard method? (4) what are the limits of reliability of the estimation of the water vole abundance by surface indices?

\section{Material and methods}

\section{Data collection}

The activity of the water vole varies throughout the year. Intense burrowing and tumulus building are subsequent to rainfalls heavy enough to reduce the summer dryness of the soil. Therefore burrowing is at its maximum in autumn and at the beginning of winter. Vegetation is at its shortest during these seasons and hardly disturbs the observation of indices. All the traplines were then set from October to February, from 1990 to 1993 , in Auvergne $\left(45^{\circ} 25^{\prime} \mathrm{N}, 2^{\circ} 30^{\prime} \mathrm{E}\right)$ and in Franche-Comté $\left(47^{\circ} 00^{\prime} \mathrm{N}, 6^{\circ} 00^{\prime} \mathrm{E}\right)$, France, in grasslands with deep soils $(>30 \mathrm{~cm})$, and in areas where the technicians of the S.R.P.V. (Services de protection de végétaux du Ministère de l'agriculture - the crop protection service of the Ministry of Agriculture) usually worked. Trap lines were set according to the standard method (Pascal and Meylan 1986, see description above), using Sherman traps or tongs traps in some occasions in Auvergne. In this region, trapping was carried out by the technicians of the S.R.P.V. and by farmers. In Franche-Comté, trapping was done only by technicians. In every case, indices were independently recorded on the $100 \mathrm{~m}$ line, which was trapped afterwards.

In order to find a method which is easy to carry out on a wide scale the choice of indices involves two constraints. The first constraint is that every index must be readable on the ground without opening the burrows and galleries. Considering Meylan (1965, 1977), Mead-Briggs and Woods (1973), Airoldi et al. (1976), Saucy and Meylan (1987), Saucy (1988), Gorman and Stone (1990), and after several interviews with the engineers and with the technicians of the S.R.P.V., we have kept the 9 following indices:

(1) Surface occupied by the tumulus network.

(2) Number of tumulus.

(3) Is the tumulus distribution linear or not? The mole is known to usually build its molehill along a line, unlike the water vole, which builds tumulus in clusters.

(4) Are tumulus in contact or not? Molehills are generally well separated from each other.

(5) Number of fresh tumulus. Freshness can be determined by the earth colour (wetter) and by evaluating the erosion of the earth hill.

(6) Is the shape of tumulus conic or flat? Molehills are usually conic and the tumulus of the water vole flat.

(7) Are "earth sausages" to be found in fresh tumulus? When burrowing a tunnel, the mole pushes a quantity of earth in front of itself and expells it inside the molehill so that molehills contain "earth sausages", shaped by the tunnel. The water vole pushes soil with its hind feet and its teeth, in such a way that tumulus do not contain "earth sausages".

(8) Are cut roots and rootlets to be found, mixed in with the earth in the tumulus? The water vole will not leave them because it eats them.

(9) Can galleries be detected at a depth of about $5 \mathrm{~cm}$ by digging into the ground with the heel? The mole burrows just under the surface of the ground in order to catch invertebrates. This kind of tunnel uplifts the surface of the ground and is easily observed. The water vole burrows numerous galleries situated at a depth of about $5-10 \mathrm{~cm}$. These galleries are not visible on the surface. However these can be detected by hitting the ground with the heel.

The second constraint is that the values of indices must be easily and quickly recorded. This is why the choice of the values of each variable is binary, except for the number of captures of voles and moles (Table 1). 
Table 1. Variables used in the field and transformed variables used in the analyses. ${ }^{1}$ binary variables.

\begin{tabular}{ccccc}
\hline \multicolumn{2}{c}{ Square $(5 \times 5 \mathrm{~m})$} & & & \multicolumn{2}{c}{ Trap line (20 squares) } \\
\hline Type of data & Variable $^{1}$ & & Variable & Values \\
\hline
\end{tabular}

\section{INDICES}

(1) Surface covered by tumulus

$\begin{array}{rr}0 \% & \text { Sc0 } \\ 1-25 \% & \text { Sc1 } \\ 26-50 \% & \text { Sc2 } \\ 51-75 \% & \text { Sc3 } \\ 76-100 \% & \text { Sc4 }\end{array}$

$\begin{array}{cc}\text { S0 } & \sum \mathrm{Sc} 0 \\ \text { S1 } & \sum \mathrm{Sc} 1 \\ \text { S2 } & \sum \mathrm{Sc} 2 \\ \text { S3 } & \Sigma \mathrm{Sc} 3 \\ \text { S4 } & \Sigma \mathrm{Sc} 4 \\ \text { S } & \text { Average surface }\end{array}$

(2) Tumulus number

$\begin{aligned} 0 & \text { Nc0 } \\ 0-5 & \text { Nc1 } \\ 6-10 & \text { Nc2 } \\ 11-20 & \text { Nc3 } \\ 21-40 & \text { Nc4 } \\ 41-60 & \text { Nc5 }\end{aligned}$

$\begin{array}{cc}\text { N0 } & \Sigma \mathrm{Nc} 0 \\ \mathrm{~N} 1 & \Sigma \mathrm{Nc} 1 \\ \mathrm{~N} 2 & \Sigma \mathrm{Nc} 2 \\ \mathrm{~N} 3 & \Sigma \mathrm{Nc3} \\ \mathrm{N} 4 & \Sigma \mathrm{Nc4} \\ \mathrm{N} 5 & \Sigma \mathrm{Nc5} \\ \mathrm{N} & \text { Average number }\end{array}$

(3) Tumulus distribution not linearly distributed linearly distributed

Lc0

L0

$\Sigma$ Lc0

(4) Distance between tumulus not juxtaposed
juxtaposed

Jc0

L1

$\Sigma$ Lc1

(5) Tumulus freshness

$$
\begin{array}{r}
\text { not any recent } \\
\text { one or two recent } \\
\text { more than two recent }
\end{array}
$$

J0

$\Sigma \mathrm{Jc} 0$

Jc1

J1

$\Sigma J \mathrm{~J} 1$

(6) Tumulus shape

$\mathrm{Fc} 2$

F0

$\Sigma \mathrm{Fc} 0$

F1 $\quad \Sigma \mathrm{Fc} 1$

F2 $\quad \Sigma \mathrm{Fc}$

Apc

Ap

$\Sigma \mathrm{Apc}$

conic

Coc

Co

$\Sigma$ Coc

(7) "Earth sausage"

absent

$\mathrm{Bc} 0$

B0

$\Sigma \mathrm{Bc} 0$

present

$\mathrm{Bc} 1$

B1

$\Sigma \mathrm{Bc} 1$

(8) Cut rootlets

absent
present

$\mathrm{Hc} 0$

HO

$\Sigma \mathrm{Hc} 0$

$\mathrm{Hc1}$

H1

$\Sigma \mathrm{Hc1}$

(9) Gallery that can be detected by digging into the ground with heel

$\begin{array}{rlll}\text { absent } & \text { Gc0 } & \text { G0 } & \Sigma \text { Gc0 } \\ \text { present } & \text { Gc1 } & \text { G1 } & \Sigma \text { Gc1 }\end{array}$

\section{CAPTURES}

(10) Number of water voles

Atc

At

$\Sigma$ Atc

(11) Number of moles

Tec

$\Sigma$ Tec 


\section{Data treatment}

Data transformations

The mole and the water vole can share, more or less temporarily, the same network of galleries. The home range of the mole is much wider than the elementary sampling unit (a square of $5 \times 5 \mathrm{~m}$ ) used in this study (Fritschy and Meylan 1980) according to the standard method (Pascal and Meylan 1986). Therefore it would be irrelevant to compare the number of captures at the scale of the elementary square to an index collected on the same limited scale. Indices recorded at the scale of the elementary sampling square were used to calculate synthetic indices (line variables) on the scale of the whole trap line (Table 1). The average surfaces occupied by tumulus are equal to the sum of the products "median of class $\times$ number of squares where the class is represented", divided by the total number of squares (20). Average tumulus numbers were computed in the same way. The values of all the other line variables are the sum of the values of the variables of the 20 squares.

\section{Comparison between data from Auvergne and data from Franche-Comté}

Data were collected in two different regions. Therefore, it was necessary to check if they presented the same general structure, especially when considering the relationships between indices. Two matrices "variables (columns) x trap lines (rows)" were established respectively corresponding to Auvergne and to Franche-Comté. These matrices were treated separately by performing a correspondence analysis (Legendre and Legendre 1984). The homogeneity of the structure of the set of data was tested by measuring the correlation between the factorial coordinates of the variables of one region and the factorial coordinates of the other, for each of the first three factorial axes. Multivariate analysis was performed using the Macmul software (Thioulouse 1989).

\section{Differences between mole indices and water vole indices}

The relationship between any index variables and the number of captures of moles and of ground voles was measured by the Pearson's linear correlation (Geller 1979). In order to consider all the variables together, and not separately, we carried out a normalized Principal Component Analysis (Legendre and Legendre 1984), using the ADE software (Dolédec and Chessel 1993) and we drew the positions of the variables according to the factorial axes 1 and 2, which presented the highest inertia. The proximity of several variables on this plan, close to correlation circle, indicates that they are highly correlated. If correlation is negative, variable vectors are opposed. If there is no correlation between variables, variable vectors are at an angle of 90 .

\section{Estimation model of water vole abundance}

We looked first for the linear combinations of index variables that were best correlated to water vole abundance by stepwise regression. At each step of the regression, the variable with the highest partial correlation was inserted in the model if its partial Snedecor's $F$ exceeded a given value. After the insertion any variable currently in the model was examined for removal, based on whether its partial $F$ was less than a defined value. Here, the probability of insertion or of exclusion was defined 0.05 (say, the value of $F$ was 4 or higher to enter, and less than 4 to remove) (Tomassone 1989). This method establishes the best regression model to predict vole abundance by using indices and it gives the variance of the estimates, too.

Agronomists use density classes (individuals/ha) in order to ground their decisions on rodent population controls in grasslands. Class limits are 0-99 (low density), 100-199 (medium density: area whose evolution is to be monitored), 200 and more (high density: control is advised). Therefore, we have tested the reliability of the model by computing the ratio of lines that were classified correctly in comparison with the classification obtained from trapping.

Stepwise regression, even though it enabled us to obtain a model with an optimal combination of variables, does not guarantee that the combination is the only possible one. We tried to simplify the 
method and looked for other predictive models by using other indices which would be simpler, while maintaining an acceptable reliability and robustness.

\section{Results}

Totally, 71 trap lines were set: 38 lines in Franche-Comté, 7 of which lacked some variables (Sc, Jc, Hc, cf Table 1) and 33 lines in Auvergne. These lines caught 1255 water voles and 73 moles.

Comparison between data from Auvergne and data from Franche-Comté

The analysis of the distribution of line numbers according to capture numbers in the two regions shows that the lines from Auvergne generally present lower

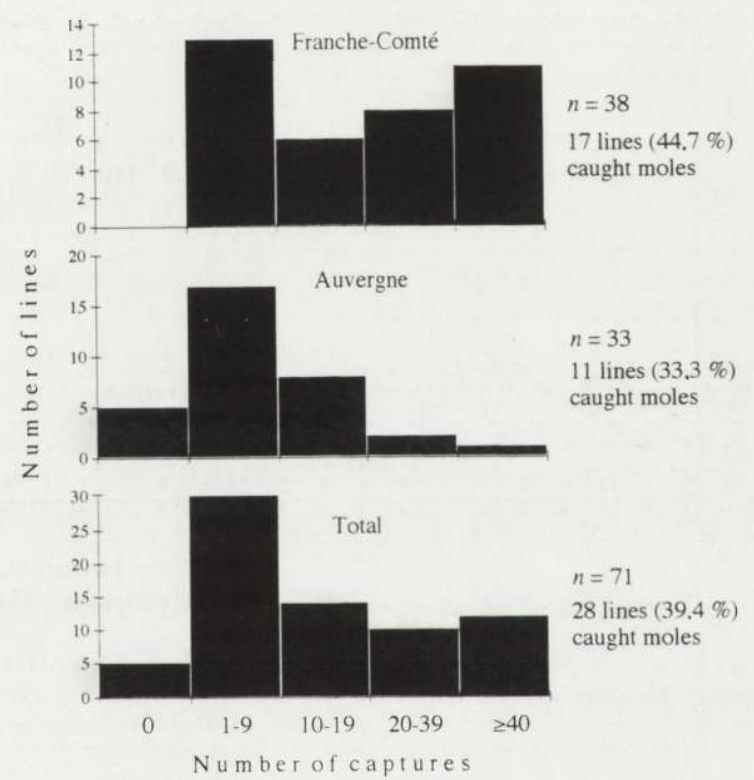

Fig. 1. Number of trap lines according to classes of water vole abundance.

densities of the water vole than those from Franche-Comté (Fig. 1). In this chapter, we will use only the 64 trap lines whose variables are fully recorded (33 lines from Auvergne and 31 lines from Franche-Comté).

A correspondence analysis was performed separately on the matrices from Auvergne and from Franche-Comté [30 variables (columns) $\times 64$ trap lines (rows)]. The comparison between the factorial coordinates of Franche-Comté variables and those of Auvergne shows that the correlations are statistically highly significant (Table 2). The first three axes, at least, are concerned, and represent $70.3 \%$ of the total inertia in Franche-Comté and 79.8\% in Auvergne. Fig. 2 also shows that the 
Table 2. Comparison between factorial coordinates obtained after separate factorial analyses of matrices, respectively from Auvergne and from Franche-Comté. FC - Franche-Comté, AV - Auvergne, Inertial \% - inertial percentage in each analysis, $r$ - correlation coefficient, $F$ - Snedecor's $F, p$ - probability of $F$.

\begin{tabular}{|c|c|c|c|c|c|c|}
\hline & \multicolumn{2}{|c|}{ Axis 1} & \multicolumn{2}{|c|}{ Axis 2} & \multicolumn{2}{|c|}{ Axis 3} \\
\hline & $\mathrm{FC}$ & $\mathrm{AV}$ & $\mathrm{FC}$ & $\mathrm{AV}$ & FC & AV \\
\hline Intertial \% & 49.9 & 43.8 & 12.4 & 25.7 & 8.0 & 10.3 \\
\hline$r$ & \multicolumn{2}{|c|}{0.76} & \multicolumn{2}{|c|}{0.75} & \multicolumn{2}{|c|}{0.71} \\
\hline$F$ & \multicolumn{2}{|c|}{37.7} & \multicolumn{2}{|c|}{36.3} & \multicolumn{2}{|c|}{28.3} \\
\hline$p$ & \multicolumn{2}{|c|}{0.0001} & \multicolumn{2}{|c|}{0.0001} & \multicolumn{2}{|c|}{0.0001} \\
\hline
\end{tabular}

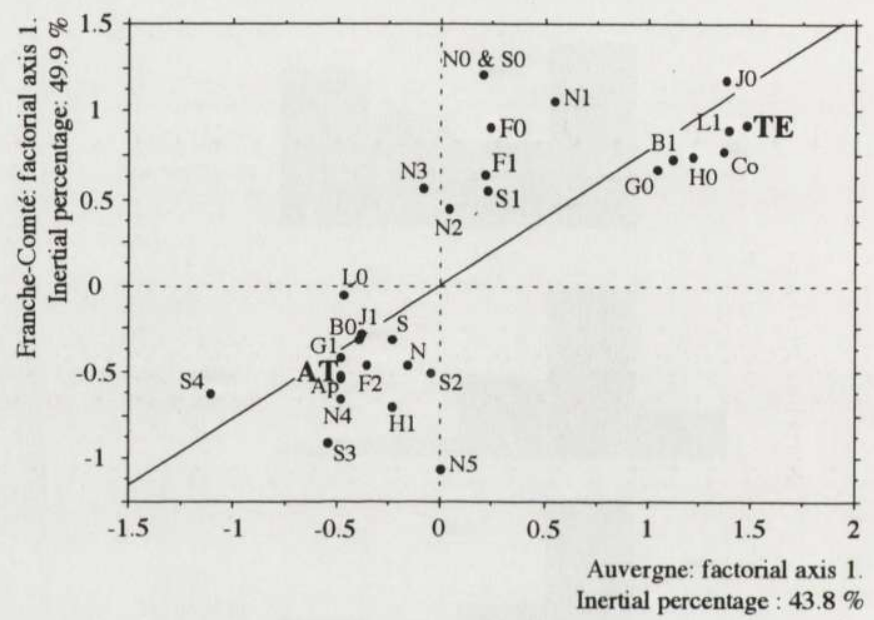

Fig. 2. Linear regression of the factorial coordinates obtained from the matrix of Auvergne and of Franche-Comté according to factorial axis 1.

coordinates on axis 1 separate a set of variables linked to the presence of the mole and an other set linked to the presence of the water vole.

These results, taken as a whole, show that data from Auvergne and from Franche-Comté present the same organization. Consequently, the two sets of data have been pooled in further analyses.

\section{Differences between mole indices and water vole indices}

Correlations between indices and water voles numbers are the best for the variables $\mathrm{S}, \mathrm{N}, \mathrm{J} 1, \mathrm{Ap}$ and $\mathrm{B} 0$ (Table 3). The variables are $\mathrm{J} 0, \mathrm{C} 0$ and $\mathrm{B} 1$ for the mole. The normalized principal component analysis on the matrix "30 variables $\times 64$ trap lines" points out a cluster of variables highly correlated to the presence of the mole. An other cluster, well separated from the precedent, is highly 
Table 3. Correlations of the index variables between water vole and mole abundances. Bold face numbers underline remarkable correlations. $n$ - number of lines, $r$ - correlation coefficient, $p$ - probability.

\begin{tabular}{|c|c|c|c|c|c|}
\hline \multirow{2}{*}{ Variable } & \multirow{2}{*}{$n$} & \multicolumn{2}{|c|}{ Arvicola terrestris } & \multicolumn{2}{|c|}{ Talpa europaea } \\
\hline & & $r$ & $p$ & $r$ & $p$ \\
\hline So & 64 & -0.63 & 0.0001 & -0.18 & 0.15 \\
\hline $\mathrm{S} 1$ & 64 & -0.22 & 0.08 & 0.36 & 0.03 \\
\hline $\mathrm{S} 2$ & 64 & 0.47 & 0.0001 & -0.08 & 0.54 \\
\hline S3 & 64 & 0.68 & 0.0001 & -0.08 & 0.56 \\
\hline $\mathrm{S} 4$ & 64 & 0.39 & 0.001 & -0.15 & 0.23 \\
\hline S & 64 & 0.79 & 0.0001 & -0.09 & 0.50 \\
\hline N0 & 71 & -0.64 & 0.0001 & -0.15 & 0.23 \\
\hline N1 & 71 & -0.50 & 0.0001 & 0.54 & 0.0001 \\
\hline N2 & 71 & -0.18 & 0.12 & 0.17 & 0.16 \\
\hline N3 & 71 & 0.29 & 0.01 & 0.06 & 0.64 \\
\hline N4 & 71 & 0.60 & 0.0001 & -0.21 & 0.08 \\
\hline N5 & 71 & 0.48 & 0.0001 & -0.11 & 0.38 \\
\hline $\mathrm{N}$ & 71 & 0.78 & 0.0001 & -0.18 & 0.14 \\
\hline L0 & 71 & 0.75 & 0.0001 & -0.22 & 0.07 \\
\hline L1 & 71 & -0.37 & 0.0017 & 0.60 & 0.0001 \\
\hline J0 & 71 & -0.43 & 0.0002 & 0.76 & 0.0001 \\
\hline J1 & 67 & 0.80 & 0.0001 & -0.39 & 0.001 \\
\hline F0 & 71 & -0.25 & 0.03 & 0.22 & 0.07 \\
\hline F1 & 71 & -0.11 & 0.35 & 0.22 & 0.07 \\
\hline F2 & 71 & 0.65 & 0.0001 & -0.13 & 0.26 \\
\hline Ap & 71 & 0.77 & 0.0001 & -0.44 & 0.0001 \\
\hline Co & 71 & -0.27 & 0.02 & 0.70 & 0.0001 \\
\hline B0 & 71 & 0.78 & 0.0001 & -0.42 & 0.0002 \\
\hline B1 & 71 & -0.25 & 0.04 & 0.70 & 0.0001 \\
\hline Ho & 71 & -0.00 & 0.98 & 0.44 & 0.0001 \\
\hline H1 & 71 & 0.53 & 0.0001 & -0.33 & 0.0057 \\
\hline G0 & 71 & -0.19 & 0.12 & 0.56 & 0.0001 \\
\hline G1 & 71 & 0.69 & 0.0001 & -0.38 & 0.001 \\
\hline AT & 71 & & & -0.35 & 0.0028 \\
\hline
\end{tabular}

correlated to the presence of the water vole. Finally, two variables (N0 and S0) are situated opposite the two other clusters. These last two variables characterize the low density of the two species (Fig. 3).

These results show that the most characteristic indices of water vole numbers are the number of tumulus $(\mathrm{N})$, the surface occupied by tumulus $(\mathrm{S})$, the absence of linearly distributed tumulus (L0), the presence of touching tumulus (J1) and flat dome shaped ones (Ap), and the absence of "earth sausages" (B0). Molehills however are clearly separated from each other (J0), cone-shaped $(\mathrm{Co})$, and often contain "earth sausages" (B1). Their linear distribution is frequently recorded (L1). 


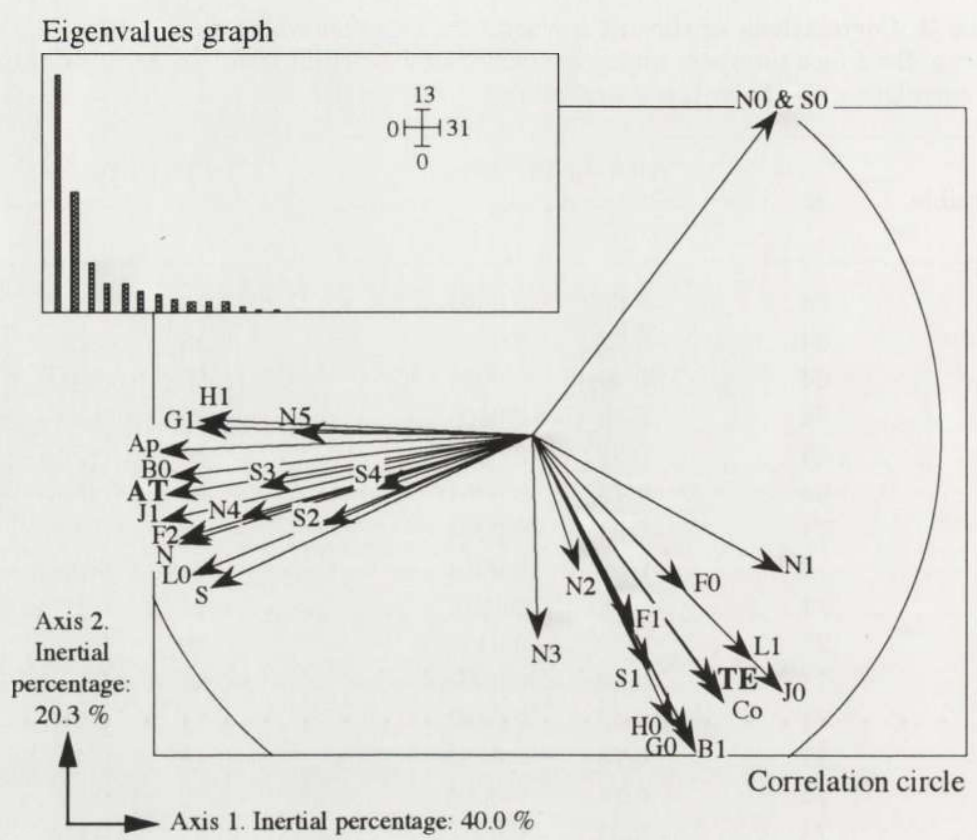

Fig. 3. Factorial diagram $(\mathrm{F} 1 \times \mathrm{F} 2)$, from the normalized principal component analysis, pooling data from Auvergne with data from Franche-Comté.

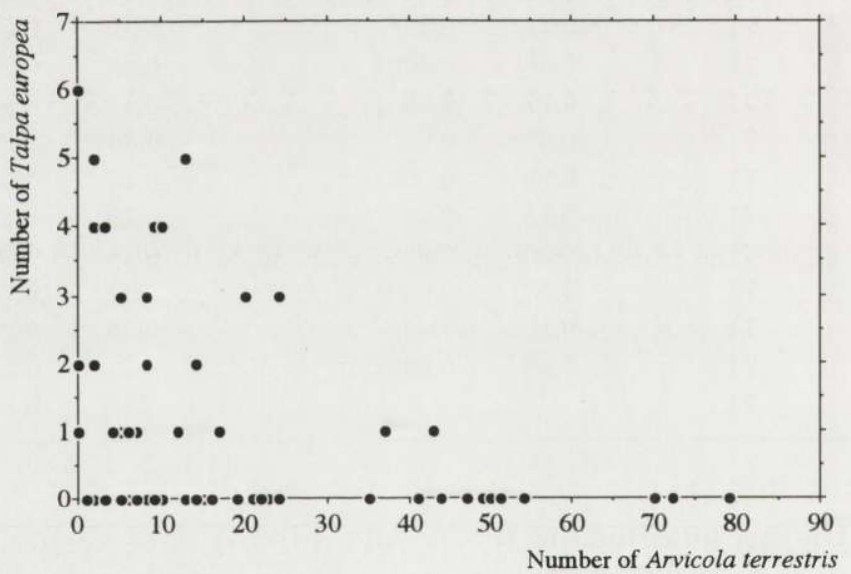

Fig. 4. Line by line comparison of the number of mole captures with the number of water vole captures $(n=71)$.

For any line of Fig. 4 the comparison betweeen the number of water vole captures and the number of mole captures shows that high densities of the water vole exclude the presence of the mole. Conversely, the highest mole abundances are recorded in lines that captured only few water voles. Both species seem to be inclined to exclude each other. 
Now, it is important to note however to what extent water voles can use mole galleries without leaving specific indices on the surface of the ground. Among the 71 trap lines, $23(32.4 \%)$ captured simultaneously both species, and $7(9.9 \%)$ moles only. The surface occupied by tumulus $(\mathrm{S})$, their number $(\mathrm{N})$, or the absence of lines of molehill (L0) characterize more water vole abundance at medium and high densities, than its presence at low density. Therefore, we have rejected these variables and we have kept indices that were more independent of density, such as the presence of juxtaposed tumulus (J1), their flat dome shape (Ap), or the absence of "earth sausages" (B0). Among the 71 trap lines, only 3 lines did not present any of these three criteria. One captured only 2 moles, the two others respectively caught 2 water voles and 4 moles, and 2 water voles and 2 moles. Any trap line having caught more than 2 water voles (that is about $20 \mathrm{ind} / \mathrm{ha}$ ), presents typical indices of the species.

\section{Estimation model of water vole abundance}

The 64 lines whose variables were completed, have been used to determine the best linear combination correlated to water vole abundance. The stepwise regression shows that the correlation is very high as soon as the first variable (F2) is introduced $(r=0.86)$. Inserting new variables (B0, N5 and S4) little improves the model (Table $4 \mathrm{a})$.

Table 4. Results of the stepwise regression and comparison of the classification computed from the regression model with the classification obtained from trapping results. (a) regression equations at each step $(r$ - correlation coefficient, AT - number of A. terrestris, SD - standard deviation, $F$ - Snedecor's $F$ ), (b) comparison of the classifications obtained according to 3 classes of density.

(a)

\begin{tabular}{lclcc}
\hline Step $\mathrm{n}^{\circ}$ & $r$ & Regression equations & SD & $F$ \\
\hline 1 & 0.86 & $\mathrm{AT}=2.22 \mathrm{~F} 2+1.73$ & 8.47 & 181.73 \\
2 & 0.89 & $\mathrm{AT}=1.66 \mathrm{~F} 2+0.8 \mathrm{~B} 0-1.93$ & 7.65 & 118.89 \\
3 & 0.90 & $\mathrm{AT}=1.43 \mathrm{~F} 2+0.99 \mathrm{~N} 5+\mathrm{B} 00.76-1.03$ & 7.28 & 90.06 \\
4 & 0.92 & $\mathrm{AT}=1.49 \mathrm{~S} 4+1.38 \mathrm{~N} 5+1.12 \mathrm{~F} 2+0.8 \mathrm{~B} 0-0.57$ & 6.89 & 77.5 \\
\hline
\end{tabular}

(b)

\begin{tabular}{cccc}
\hline \multirow{3}{*}{$n=64$} & \multicolumn{3}{c}{ Calculated groups } \\
\cline { 2 - 4 } & $\mathrm{C} 1$ & $\mathrm{C} 2$ & $\mathrm{C} 3$ \\
& $<10$ & $10-19$ & $\geq 20$ \\
\hline
\end{tabular}

\begin{tabular}{|c|c|c|c|c|}
\hline \multicolumn{5}{|c|}{ Observed groups } \\
\hline C1 & $<10$ & 31 & 4 & 0 \\
\hline $\mathrm{C} 2$ & $10-19$ & 3 & 9 & 1 \\
\hline C3 & $\geq 20$ & 0 & 3 & 13 \\
\hline Under & estimations: & $9 \%$ & & \\
\hline Overe & timations: & $8 \%$ & & \\
\hline Corre & & $83 \%$ & & \\
\hline
\end{tabular}


In order to determine the limits within which abundance classes could be used, we compared the results of the classification obtained according to the model predictions (calculated groups) with the results actually observed from trapping (observed groups). Taking four classes $(0-9,10-19,20-39, \geq 40$ captures) into account led to a $77 \%$ ratio of correct classification. Pooling the highest densities (classe 3 and 4 ) led to a ratio of $83 \%$ (Table $4 \mathrm{~b}$ ). Classification mistakes appeared only in the adjacent cells of the table.

\section{Towards a simplified model}

The regression model applied to the complete 64 trap lines gives a correlation to abundance of 0.86 to the variable F2 (Table 4a). If we use the 71 trap lines, for this variable only, the correlation drops to 0.65 (Table 3 ). It is then much lower than the correlation with other variables which therefore could seem to be better to estimate water vole abundance. The variables that give the best correlation to abundance are $\mathrm{J} 1, \mathrm{Ap}, \mathrm{B} 0$. However, on the scale of a sampling square, they are more characteristic of the presence of the water vole than of its abundance. The best correlations are obtained from the logarithm of abundance (Table 5a). The regression equations that involve those variables are very similar (Table $5 \mathrm{~b}$ ). On a practical basis we can consider those variables as being equivalent (Table $5 \mathrm{c}$ ).

Table 5. Correlations of the best index variables of Table 2 with water vole abundance and with the logarithm of abundance +1 . (a) linear correlations and standard deviation of residuals $(n$ - number of trap lines, $r$ - correlation coefficient, $\mathrm{SD}$ - standard deviation), (b) regression equation of the three best variables and maximum limit of sensitivity of the method, (c) correlation between the three variables. Bold face numbers correspond to the highest values of $r$.

(a)

\begin{tabular}{|c|c|c|c|c|c|}
\hline \multirow{2}{*}{ Variable } & \multirow{2}{*}{$n$} & \multicolumn{2}{|c|}{ Number of voles } & \multicolumn{2}{|c|}{$\begin{array}{l}\text { Natural logarithm of } \\
1+\text { number of voles }\end{array}$} \\
\hline & & $r$ & $\begin{array}{l}\text { residuals } \\
\quad \mathrm{SD}\end{array}$ & $r$ & $\begin{array}{l}\text { residuals } \\
\quad \mathrm{SD}\end{array}$ \\
\hline S & 64 & 0.79 & 10.22 & 0.65 & 0.83 \\
\hline $\mathrm{N}$ & 71 & 0.78 & 11.92 & 0.69 & 0.82 \\
\hline $\mathrm{F} 2$ & 71 & 0.65 & 14.52 & 0.63 & 0.88 \\
\hline J1 & 67 & 0.80 & 10.78 & 0.89 & 0.52 \\
\hline Ap & 71 & 0.77 & 12.16 & 0.84 & 0.62 \\
\hline B0 & 71 & 0.78 & 12.02 & 0.84 & 0.62 \\
\hline
\end{tabular}

(b)

\begin{tabular}{lcc}
\hline Variable & Regression equations & $\begin{array}{c}\text { Theoretical } \\
\text { maximum } \\
\text { sensitivity }\end{array}$ \\
\hline J1 & $\ln (1+\mathrm{AT})=0.14 \mathrm{~J} 1+0.87$ & 38 \\
Ap & $\ln (1+\mathrm{AT})=0.13 \mathrm{AP}+1.24$ & 46 \\
B0 & $\ln (1+\mathrm{AT})=0.14 \mathrm{~B} 0+1.06$ & 46 \\
\hline
\end{tabular}

(c)

\begin{tabular}{cccc}
\hline & J1 & Ap & B0 \\
\hline J1 & 1 & & \\
Ap & 0.90 & 1 & \\
B0 & 0.91 & 0.88 & 1 \\
\hline
\end{tabular}


The standard trap line being made of 20 squares, enables us to determine what is the theoretical maximum sensitivity of the estimation method at this scale. This corresponds to the case when a binary variable is coded as one in every square. This theoretical sensitivity cannot exceed 38 to 46 captures (Table $5 \mathrm{~b}$ ). As it has been underlined in the above chapter this result explains why we cannot increase the number of classes in high densities. The line is saturated as soon as water vole density exceeds about $400 \mathrm{ind} / \mathrm{ha}$.

Fig. 5 shows the graph of the regression for variable J1. Table 6 shows that this model allows the use of 3 abundance classes, with a $87 \%$ ratio of correct classification. This value is nearly the same as the one obtained by stepwise regression (Table 4a).

$$
\ln (1+\mathrm{AT})=0.14 \mathrm{~J} 1+0.87
$$

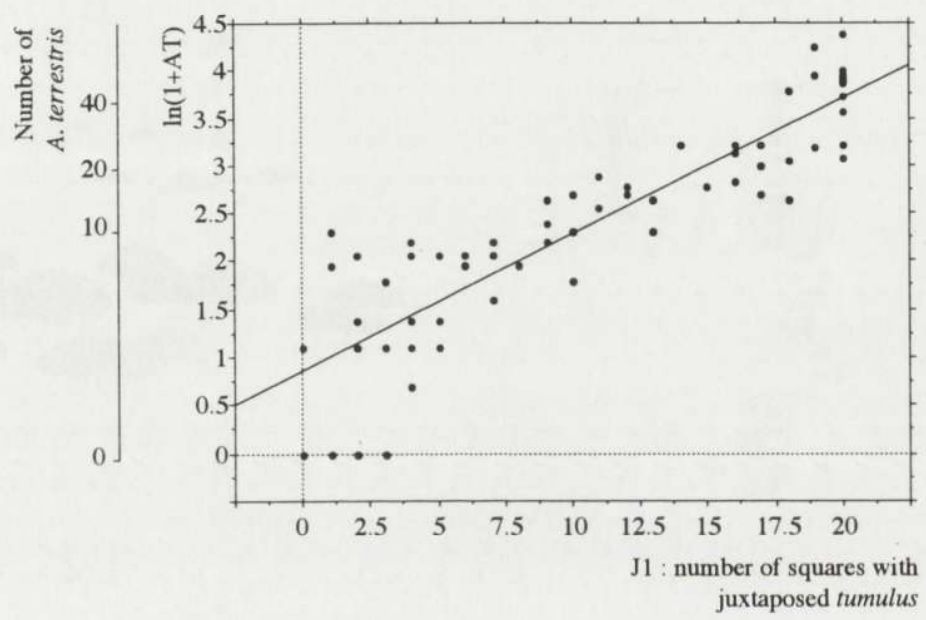

Fig. 5. Graph of the linear regression $\ln (1+\mathrm{AT})=\mathrm{f}(\mathrm{J} 1), n=67$.

Table 6. Comparison of the classifications obtained according to 3 abundance classes, from the regression model of Fig. 5, with the classification obtained from trapping results. $n$-number of lines.

\begin{tabular}{|c|c|c|c|}
\hline \multirow[b]{2}{*}{$n=67$} & \multicolumn{3}{|c|}{ Calculated groups } \\
\hline & $\begin{array}{c}\text { G1 } \\
<10\end{array}$ & $\begin{array}{c}\text { G2 } \\
10-19\end{array}$ & $\begin{array}{c}\text { G3 } \\
\geq 20\end{array}$ \\
\hline \multicolumn{4}{|l|}{ Observed groups } \\
\hline G1 $<10$ & 34 & 1 & 0 \\
\hline G2 $10-19$ & 3 & 6 & 4 \\
\hline G3 $\geq 20$ & 0 & 1 & 18 \\
\hline Underestimations: & $6 \%$ & & \\
\hline Overestimations: & $7 \%$ & & \\
\hline Correct: & $87 \%$ & & \\
\hline
\end{tabular}




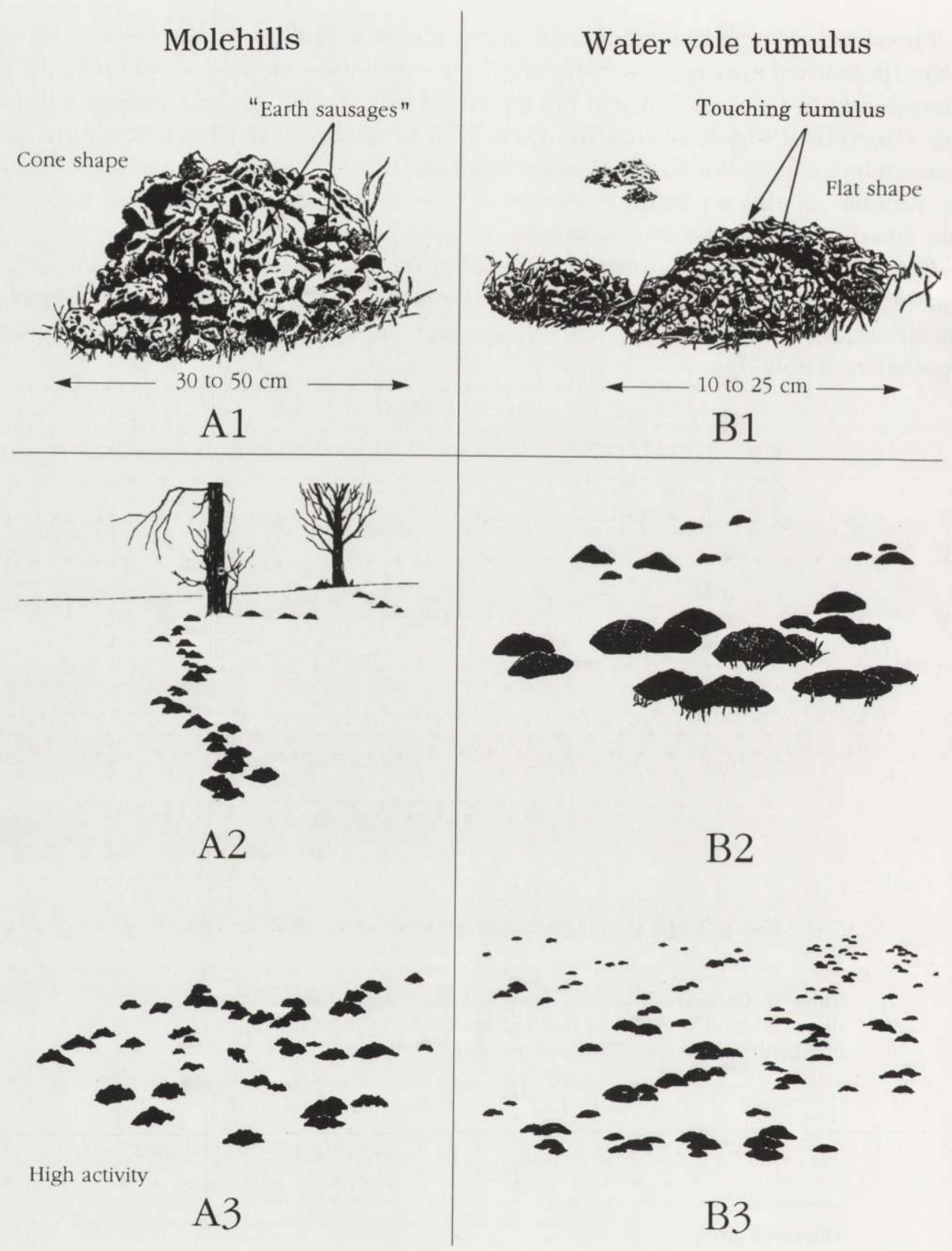

Fig. 6. Best computed criteria distinguishing mole surface indices from water vole surface indices. At the perception level of some tumulus ( $5 \times 5 \mathrm{~m}$ square), the shape, the tumulus proximity, and the presence of "earth sausages" must be taken into account (A1 and B1). At the perception level of a parcel, mole activity is characterized by the linear distribution of molehills (A2), which is to be compared with the patchy distribution of water vole tumulus (B2). At the same scale and when mole activity is high, the general distribution of molehills (A3) can be rather similar to the distribution of water vole tumulus (B3). In this case, attention must be turned onto the shape and to the proximity of tumulus. (from J. M. Michelat's original drawings). 
Consequently, the use of surface indices in order to estimate the water vole abundance is valid, within some limits exposed in the discussion. The suitable and best variable is the frequency of $5 \times 5 \mathrm{~m}$ squares with water vole tumulus. Statistically, the following criteria will be considered: the flatness of tumulus, their juxtaposition, and the absence of "earth sausages" (Fig. 6).

\section{Discussion and conclusion}

Molehills and water vole tumulus

The results provide quantitative and statistically-tested information which best differentiates molehills and water vole tumulus. They confirm methods which were used by agriculture experts (SRPV et al. 1990, Meylan 1991, Meylan and Höhn 1991). These authors also recommend the opening of tunnels and the use of their underground characteristics. For instance, the mole digs tunnels which are rather wider than high (only two fingers can be introduced into them), the water vole digs bigger tunnels, which are conversely rather higher than wide (three fingers and more can be introduced). This criterion can be useful for the beginner when he hesitates over conflicting surface criteria. This may be the case when water vole density is low and when only molehills are recorded. However, the present study shows that to open a gallery is not necessary when only rough estimates of water vole density are needed, since this species always provides specific indices at medium and high densities.

\section{Coexistence of the two species}

The increasing densities of the water vole seem to exclude the mole. Frischty and Meylan (1980) have recorded that the home range of the mole was reduced by the presence of the water voles in the same gallery network. The present study shows the ultimate consequences of this antagonism on population level.

Relationships between water vole indices and water vole densities, and their limits

This study shows that it is possible to estimate water vole densities by using surface indices. The correlation between results obtained by using capture, and results obtained by using index method is high $(0.8<r<0.9)$. The residual variance is however high, so that only three density categories are to be distinguished. The use of index method must be considered taking into account both the precision which is required for a given study (Cochran in Frontier 1983), and the practical limits of the method.

Until now, one of the limits to regional studies on water vole population kinetics was primarily technical. Estimation methods based on the capture of animals are apparently very precise at the parcel scale and give the opportunity of autopsies when it is interesting to collect some biological parameters as reproductive conditions, parasitology, etc. Results on other rodent species show that the first 
ecological parameters to play a role in population regulation are neither to be looked for within this space scale nor on this level of biological organization (Lidicker 1988). According to Lidicker, studies on rodents devoted to measuring population properties at the parcel scale, such as survival rates, birth rates, average aggressiveness, etc., and to correlate these with environmental factors, have led to a long list of conclusions, all correct, but which does not explain the pluriannual changes in density. Spitz (1972) showed that it was possible to forecast the period in the year when high densities occur for common vole Microtus arvalis, another grassland species, when one knows winter or spring reproduction precocity. However, Spitz's study was concerned with an exceptional case, that of a population witnessing a chronical pullulation, which, precisely, does not present interannual variations of abundance. No studies that have been published to this day on the water vole, or on other similar grassland species, points out reliably the role of demographic parameters in forecasting the pluriannual changes in rodent density. On the other hand, the preponderant role of global landscape variables has been underlined for common vole on the regional level (Delattre et al. 1992), or on the sectorial level (P. Delattre et al., submitted). Preliminary results show that water vole density changes are also controlled by global landscape variables concerning land use (agriculture and forestry) on the two levels (Delattre et al. 1988, Deblay and Salvi 1993). Unlike the other methods, which are technically difficult to carry out, the index method proposed here can be a powerful tool to describe demographic processes at the proper space and time scale. However, some limits must be taken into account when using it.

All the trap lines were set in grasslands with deep soil (>30 cm). The soils of Franche-Comté lay on limestone or on marl. They are relatively compact and rich in clay. The soils of Auvergne are lighter and lay on siliceous rocks of igneous or metamorphic origin. Our results take this variability into account and this shows a good robustness of this method as far as soil differences are concerned. The water vole burrows galleries in order to eat roots (Saucy 1988, Kopp 1988, 1993). We can put forward the hypothesis that, for a given density, voles produce more activity traces in very thin soils (less than $15 \mathrm{~cm}$ ). Under this hypothesis and using the index method without caution could lead to overestimate rodent density in this kind of soil. Until this hypothesis is verified, it is better to compare only similar soils, as far as soil depth and agricultural treatment are concerned.

Surface indices of the water vole are more perceptible and more numerous in autumn and winter. During these seasons, densities are at their highest (end of the reproduction season). The energy and water requirements of the water vole are considerable. These requirements reach the equivalent of 3 tons of carrots Daucus carota for $300 \mathrm{ind} / \mathrm{ha}$ (Grenot et al. 1983), during a period when there is no vegetation growth. Therefore, autumn and winter are the seasons during which foraging and storage of food are the most intense. Finally, during spring and summer, the growth of vegetation certainly allows less burrowing activity, which becomes more difficult when dryness makes surface soil horizons extremely 
compact. Within this context of seasonal variation of activity, comparing the results obtained for different seasons would be totally irrelevant.

One of the possible drawback of using tumulus as an index, is their high remanence. In the case of a rapid population decrease, surface indices would only correspond to the population density of some weeks before. For this study, 21 trap lines were set from December to February, more than 90\% (19) of them in January and February. During these months the winter decrease of the population had at least begun. Therefore, it seems that the variability caused by this potential bias is low. Good sense must lead the oberver to eliminate indices which are clearly old (tumulus devastated by erosion). Another bias may originate from cattle stamping. Cattle destroy the tunnel network and voles present a higher burrowing activity, and may even emigrate outside the parcel. The observer must avoid collecting index data in such conditions.

The mediocre precision of the method, particularily for high densities, must not prevent its use. This precision is to be compared to the density changes to be measured and these fluctuate between 0 and $1000 \mathrm{ind} / \mathrm{ha}$. Critical values have been established empirically in agronomy. In rich meadows, the threshold is situated at about $200-250 \mathrm{ind} / \mathrm{ha}$ in spring or summer. In poor meadows it is at over $100 \mathrm{ind} / \mathrm{ha}$ for the same seasons (Pascal 1984, 1988). Moreover, Weber and Aubry (1993) show that the fox Vulpes vulpes switches its diet onto the water vole when water vole density is above the threshold of 200-250 ind/ha at the scale of the station. Critical density values, in agronomy as well as in ecology, are then perfectly detectable by using the index method. In high densities, the problem posed by the saturation of sampling intervals is rather classical of index methods as well as methods of estimation of abundance based on capture (Pascal and Meylan 1986). This problem will disappear as soon as the length of sampling transects increases. For this study, the length is fixed by the standard trap line $(100 \mathrm{~m})$ which is used to calibrate the index method. However, the very high densities (much more than $400 \mathrm{ind} / \mathrm{ha}$ ) always correspond to peak values at the scale of station $(n \times 10 \mathrm{~m})$ and never to mean values observed within the whole sector $(n \times 1 \mathrm{~km})$. The index method presents the definite advantage of being suitable to space and time scale that would be incompatible with estimations from trap lines. Since it is easy to carry out, it gives for instance the possibility for every trained farmers to quickly monitor his grasslands at a low cost. In the field of research and development, the time spared to estimate a density on 1 or 2 ha from trapping (two days), can be used to draw distribution maps from wide transects and about areas of more than $25 \mathrm{~km}^{2}$. Correlated with different types of landscapes and of grassland technical treatments, those maps have the advantage of describing the interannual spatial dynamic of the population kinetics, at the proper scales. The index method may be used at its best in research programmes aiming at this last goal. On the one hand, it should allow the definition of global variables which explain population kinetics of A. terrestris (agricultural land use, landscape structure, agricultural holdings, predator distribution, etc.), 
and on the other, following Lidicker (1988), it should eventually lead to carry out the test of the hypotheses concerning short space and time scales and to look outwardly from the boundaries of the phenomenon under study. This would thereby place it in a more inclusive context. There is no doubt that these conditions are essential to achieve and improve scientific results obtained on rodent dynamics at the parcel scale.

Aknowledgements: We thank J. Caspar and S. Henriot for their help in field investigations. Drawings of Fig. 6 were made by J. M. Michelat. We are also grateful to P. Acobas and C. Durix, who kindly checked the English translation. This study has been financially supported by the Regional Council of Franche-Comté, as part of the thematic contract "Rodents and rural planning".

\section{References}

Airoldi J. P. 1976. Le terrier de la forme fouisseuse du Campagnol terrestre (Arvicola terrestris scherman Shaw) (Mammalia, Rodentia). Zeitschrift für Säugetierkunde 41: 23-42.

Airoldi J. P. 1981. Nouvelles considérations sur le terrier du Campagnol terrestre (Arvicola terrestris scherman Shaw) (Mammalia Rodentia): résultats préliminaires. La Défense des Végétaux 208: $155-161$.

Airoldi J. P. 1992. Dynamique du développement du terrier de la forme fouisseuse du Campagnol terrestre (Arvicola terrestris L.) en terrarium vertical et dans le terrain. Revue suisse de Zoologie 99: $87-108$

Airoldi J. P., Altroshi R. and Meylan A. 1976. Le comportement fouisseur du Campagnol terrestre, Arvicola terrestris scherman Shaw (Mammalia, Rodentia). Revue suisse de Zoologie 83: 282-286.

Airoldi J. P. and de Werra D. 1993. The burrow system of the fossorial form of the Water Vole (Arvicola terrestris scherman Shaw.) (Mammalia, Rodentia): an approach using theoretical methods and simulation models. Mammalia 57: 423-433.

Blondel J. 1979. Biogéographie et écologie. Masson, Paris: 1-173.

Deblay S. and Salvi D. 1993. Cinétique des populations de Campagnol terrestre (Arvicola terrestris scherman) dans le Doubs. Propositions pour une stratégie de recherche. Mémoire d'ingénieur, Institut national de promotion supérieure agricole, Dijon: 1-119.

Delattre P., Damange J. P., Pascal M. and Habert M. 1988. Rôle de la prédation et influence de la structure du paysage agraire sur le développement des cycles d'abondance d'Arvicola terrestris scherman. European Plant Protection Office Bulletin 18: 415-422.

Delattre P., Giraudoux P., Baudry J., Truchetet D., Musard P., Toussaint M., Stahl P., Poule M. L., Artois M., Damange J. P. and Quéré J. P. 1992. Land use patterns and types of Common Vole (Microtus arvalis) population kinetics. Agriculture, Ecosystem and Environment 39: 153-169.

Delattre P., Giraudoux P., Damange J. P. and Quéré J. P. 1990. Recherche d'un indicateur de la cinétique démographique des populations du Campagnol des champs (Microtus arvalis), Revue d'Ecologie (Terre et la Vie) 45: 375-384.

Dolédec S. and Chessel D. 1993. Programmathèque ADE, 3.6. tome VII. Centre national de la recherche scientifique, Lyon: 1-102.

Fritschy J. M. and Meylan A. 1980. Occupation d'un même terrier par Talpa europaea L. et Arvicola terrestris scherman (Shaw) (Mammalia). Revue suisse de Zoologie 87: 895-906.

Frontier S. 1983. Stratégies d'échantillonnage en écologie. Masson, Paris: 1-494.

Geller S. 1979. Statistique. Masson, Paris: 1-222.

Giraudoux P., Michelat D. and Habert M. 1990. La Chouette effraie (Tyto alba) est-elle un bon modèle d'étude en dynamique de population? Alauda 58: 17-20.

Gorman M. L. and Stone R. D. 1990. The natural history of moles. Cristopher Helm, London: 1-138. 
Grenot C., Pascal M., Buscarlet J. M., Francaz J. M. and Sellami M. 1983. Méthodologie appliquée à l'énergétique écologique: bilans hydriques et énergétique du Campagnol terrestre dans un agroécosystème de moyenne altitude. Bulletin de la Societé d' Ecophysiologie 8: 75-105.

Habert M. 1988. Fondement des réseaux d'alerte et évolution des densités du Campagnol terrestre en France. European Plant Protection Office Bulletin 18: 423-427.

Hanski I. and Tiainen J. 1988. Populations and communities in changing agroecosystems in Finland. Ecological Bulletins 39: 159-168.

Hansson L. and Hentonnen H. 1985. Gradients in density variations of small rodents: the importance of latitude and snow cover. Oecologia (Berlin) 67: 394-402.

Kopp R. 1988. Les choix alimentaires de la forme fouisseuse du Campagnol terrestre (Arvicola terrestris scherman): essais en terrarium. European Plant Protection Office Bulletin 18: 393-400.

Kopp R. 1993. Etude de l'impact de la forme fouisseuse du Campagnol terrestre, Arvicola terrestris scherman (Shaw), sur la végétation d'une prairie. Ph. D. thesis, Lausanne: 1-120.

Legendre L. and Legendre P. 1984. Ecologie numérique: tome 2, la structure des données écologiques. Masson, Paris: 1-247.

Lidicker W. Z. 1988. The synergistics effects of reductionist and holistic approaches in animal ecology. Oikos 53: 278-281.

Lidicker W. Z. and Anderson P. K. 1962. Colonization of an island by Microtus californicus, analyzed on the basis of runway transects. Journal of Animal Ecology 31: 503-517.

Liro A. 1974. Renewal of burrows by the common vole as the indicator of its number. Acta Theriologica 19: 259-272.

Mackin-Rogalska R., Adamczewska-Andrzejewska K. and Nabagło L. 1986. Common vole numbers in relation to the utilization of burrow systems. Acta Theriologica 31: 17-44.

Mead-Briggs A. R. and Woods J. A. 1973. An index of activity to assess the reduction in mole numbers caused by control measures. Journal of Applied Ecology 10: 837-845.

Meylan A. 1965. Les terriers de trois espèces de petits mammiferes. Agriculture Romande 4: 1-48.

Meylan A. 1977. Le Campagnol terrestre. Arvicola terrestris (L.): biologie de la forme fouisseuse et méthodes de lutte. Revue suisse d'Agriculture 9: 178-187.

Meylan A. and Höhn H. 1991. Taupe et Campagnol terrestre. Rev. suis. viti. arb. hort. 1: 2.

Pascal M. 1984. Méthode d'échantillonnage de la forme fouisseuse du Campagnol terrestre (Arvicola terrestris scherman); recherche d'un estimateur de la densité pour un piégeage en bande. Acta Oecologica/Oecologia applicata 6: 143-163.

Pascal M. 1988. Bilan des recherches menées par le groupe inter-organismes ACTA-INRA-SPV sur la biologie d'Arvicola terrestris scherman en France (1979-1987). European Plant Protection Office Bulletin 18: 381-392.

Pascal M. and Meylan A. 1986. L'échantillonnage linéaire des populations de la forme fouisseuse du Campagnol terrestre (Arvicola terrestris scherman Shaw). La Défense des Végétaux 237: 3-12.

Pascal M., Pradier B., Habert M. and Vallat H. 1985. Le Campagnol terrestre: premiers résultats des réseaux d'observation des régions Franche-Comté et Auvergne-Limousin (1983-1984). La Défense des Végétaux 231: 1-8.

Rodolphe F. and Pascal M. 1985. Méthode d'échantillonnage de la forme fouisseuse du Campagnol terrestre (Arvicola terrestris scherman); recherche des limites d'utilisation de la méthode. Acta Oecologica/Oecologia applicata 5: 303-317.

Saucy F. 1988. Dynamique de population, dispersion et organisation sociale de la forme fouisseuse du Campagnol terrestre (Arvicola terrestris scherman). Ph. D. thesis, Neuchâtel: 1-366.

Saucy F. and Meylan A. 1987. Quelques aspects de la biologie d'Arvicola terrestris scherman (Shaw), (Mammalia, Rodentia), révélés par les piégeages et les signes d'activité sous la neige. Bulletin de la Societé vaudoise des Sciences Naturelles 78: 381-417.

Seber G. A. F. 1982. The estimation of animal abundance and related parameters. Griffin \& Co, London: $1-654$. 
Spitz F. 1972. Démographie du Campagnol des champs, Microtus arvalis, en Vendée. Annales de Zoologie et d'Ecologie animale 6: 259-312.

SRPV, FREDEC Franche-Comté, ACTA, INRA 1990. Le Campagnol terrestre en prairies, Arvicola terrestris. Fiche phytosanitaire, Ministère de l'Agriculture et de la Forêt, Paris 1-2.

Teivanen T. 1979. Vole damage to forest seedlings in reforested areas and fields in Finland in the years 1973-76. Folia forestalia 387: 1-23.

Thioulouse J. 1989. Statistical analysis and graphical display of multivariate data on the Macintosh. Computer application in biosciences 5: 287-292.

Tomassone R. 1989. Comment interpréter les résultats d'une régression linéaire? ITCF, Paris: 1-55.

Wang X. 1993. Analyse du système Campagnol provençal (Microtus - Terricola-duodecimcostatus) à trois niveaux de perception (groupe social, population et métapopulation). $\mathrm{Ph}$. D. thesis, Montpellier: $1-166$.

Weber J. M. and Aubry S. 1993. Predation by foxes, Vulpes vulpes, on the fossorial form of the water vole, Arvicola terrestris scherman, in western Switzerland. Journal of Zoology, London 229: $553-559$.

Received 11 April 1994, accepted 25 October 1994. 